\title{
LA ARQUEOLOGÍA FILOSÓFICA: DE LA HISTORIA DE LA FILOSOFÍA A LA FILOSOFÍA ${ }^{1}$
}

\author{
Juan Vicente Cortés ${ }^{2}$ \\ Universidad Alberto Hurtado, Chile
}

Recibido: 21.03.2019 - Aceptado: 01.02.2020

\begin{abstract}
RESUMEN
El presente trabajo tiene por objetivo abordar la cuestión de las relaciones entre filosofía e historia de la filosofía, entendida esta última como disciplina filosófica. En efecto, a diferencia de lo que ocurría hace unos cincuenta años atrás, el debate entre historia de la filosofía y filosofía parece darse actualmente como un debate interno a la historia de la filosofía. Desde este punto de vista, no se trata ya de una "querella" (en la que se enfrentan dos posturas opuestas: "historia o filosofía" vs. "filosofía si historia"), sino más bien de una reflexión de aquellos que practicamos esta disciplina acerca de nuestro propio quehacer, en la medida en que nuestro quehacer es a un mismo tiempo histórico y filosófico. El problema planteado en el presente trabajo se centra en el método, e indisolublemente vinculado al método, en el objeto y en la finalidad del quehacer historiográfico en (o para la) filosofía. Me propongo defender las posiciones de la arqueología filosofía respecto de estos puntos (método, objeto y finalidad), frente a la historia de la filosofía de corte analítico.
\end{abstract}

Palabras clave: arqueología filosófica; historia de la filosofía; a priori histórico; Alain de Libera

\begin{abstract}
This work addresses the question of the relationships between philosophy and the history of philosophy, the latter understood as a philosophical discipline in the strict sense. Indeed, unlike what happened some fifty years ago, the debate between the history of philosophy and philosophy seems to be taking place today as an internal debate on the history of philosophy. From this point of view, it is no longer a "quarrel" (in which two opposing positions face: "history or philosophy" vs. "philosophy iff history"), but rather a reflection of those who practice this discipline about our own work, insofar as our work is at the same time historical and philosophical. In this regard, the problem raised in this work focuses on the method, and inextricably linked to the method, on the object and purpose of the historiographic work in (or for) philosophy. In the present work, I propose to defend the positions of archeological philosophy regarding these points (method, object and purpose), against the history of philosophy of analytical tendency.
\end{abstract}

Keywords: philosophical archeology; history of philosophy; historical a priori; Alain de Libera

${ }^{1}$ El presente trabajo forma parte del proyecto FonDECYT Iniciación (Chile), No. 11190137. - Agradezco a Carmen Ruiz por sus comentarios y a Miguel Carmona por su ayuda con la corrección del presente trabajo.

2 juan.vicente.cortes@gmail.com 
Toda relación entre dos o más cosas indica un absoluto que es esa relación misma. Ese absoluto es tan efímero o duradero como son de efímeras o duraderas las cosas y su relación. Pero es siempre absoluto por ser la ley única que fija esa relación. Juan Emar, Cavilaciones, p. 82.

...the questioning activity, the Socrates within us. R. G. Collingwood, An Autobiography, p. 35. 


\section{INTRODUCCIÓN}

Todo parece indicar que en la actualidad el problema de la relación entre filosofía e historia de la filosofía no se plantea ya en términos de oposición. La pregunta que solía hacerse en el marco de este debate era: ¿cómo debe relacionarse el filósofo con la historia de su disciplina? ${ }^{3}$ Las respuestas podían ir desde "el filósofo no debe hacer historia si quiere hacer filosofía" hasta "el filósofo sólo puede hacer filosofía haciendo la historia de su disciplina". Por el contrario, en la actualidad, ningún filósofo parece tener buenas razones para negar la importancia y el valor del quehacer del historiador de la filosofía para la filosofía y ningún historiador de la filosofía parece tener razones suficientes para afirmar la reducción de la filosofía a la historia de la filosofía. Felizmente, este debate, que se dio antaño por reacción de los filósofos que se hacen llamar "analíticos" contra cualquiera que pusiera en duda la legitimidad del uso que ellos hacían de apelaciones relativas a la historia de la filosofía para referirse a ciertos problemas, tesis o conceptos, ${ }^{5}$ ha dado paso a otro más importante. El debate entre "historia de la filosofía" y "filosofía" parece darse actualmente como un debate interno a esa disciplina llamada "historia de la filosofía", de suerte que tiene menos la forma de una "querella", que la de una reflexión de los historiadores de la filosofía acerca de su propio quehacer, en tanto quehacer a un mismo tiempo histórico y filosófico. Respecto de esto, el problema, a juicio mío, parece centrarse hoy en el método, e indisolublemente vinculado al método, en el objeto y en la finalidad del quehacer historiográfico en (o para la) filosofía.

3 Pregunta diferente a la de saber cómo relacionarse con la historia como saber y como disciplina, que da origen a la "filosofía de la historia".

4 Famoso es el chiste de Quine: "Hay dos tipos de personas que se interesan por la filosofía: las que se interesan por la filosofía y las que se interesan por la historia de la filosofía", referido por A. MacIntyre (1990, 59), en Rorty, Schneewind, Skinner (eds.) 1990. Doy también la referencia del original en inglés: 1984, 39-40.

5 Así, la tesis "platónica" en filosofía de las matemáticas según la cual "hay" objetos matemáticos abstractos independientes del matemático que los piensa o el "dogma cartesiano" del "fantasma en la máquina" en filosofía de la mente, no suelen ser justificadas a partir de los textos de Platón o de Descartes; consultar Sorrel y Rogers, 2005, 2. 
De manera muy general, se pueden distinguir dos tipos de historiografías filosóficas diferentes. ${ }^{6}$ Estos dos tipos son algo así como los dos extremos opuestos, al interior de los cuales es posible concebir una pluralidad de métodos historiográficos diversos para la filosofía. De un lado, está la historiografía que separa las preguntas de orden histórico de las preguntas de orden filosófico y, del otro, está aquella para la que toda pregunta filosófica es constitutivamente histórica. El primer tipo, promovido hoy en día principalmente por los historiadores partidarios de la "filosofía analítica", atribuye a las preguntas de orden histórico el rol de "exégesis" o "interpretación", por el cual se reconstruyen los argumentos que un autor utiliza para sostener una tesis filosófica, y a las de orden filosófico el rol de "evaluación" de la verdad o falsedad de dichas tesis. ${ }^{7}$ El segundo, en cambio, se propone determinar las condiciones que hacen que, en un momento histórico particular, un discurso filosófico se vuelva necesario. ${ }^{8}$ Esto no quiere decir que la discusión deba reducirse a una oposición entre "historiografía analítica" e "historiografía continental", no solo porque creemos que la distinción sobre la que pretende fundarse ("filosofía analítica" vs "filosofía continental") carece en realidad de toda legitimidad (Placencia 2017, 13), sino también porque hay elementos de historiografía del primer tipo entre los historiadores que son habitualmente asimilados a la "filosofía continental" y del segundo entre los que se hacen llamar a sí mismos "analíticos" (Peden 2014, 13). Sin embargo, por razones de comodidad, hablaré de "historia analítica de la filosofía" para referirme a la historiografía del primer tipo, por cuanto los historiadores del primer tipo, que reconocen explícitamente la división de los

${ }^{6}$ Es sabido que desde hace algún tiempo existe un interés creciente en "filosofía analítica" por la "historia de la filosofía" (en particular por el problema que plantea la atribución de una tesis a un autor del pasado), al punto que se ha llegado a hablar del surgimiento de una "historia analítica de la filosofía". Ver al respecto los trabajos colectivos dirigidos por Jean-Michel Vienne (1997) y por Sorrel y Rogers (2005). Mulligan (1997) y Glock (2008, 867-897) hablan explícitamente de una corriente analítica en historia de la filosofía (que Mulligan hace remontar a Bolzano y a Brentano). Usaremos la categoría "historia analítica de la filosofía" para remitir a un modelo extremo explicitado más abajo y en oposición teórica radical a la "arqueología filosófica".

${ }^{7}$ Es de notar, sin embargo, que la asimilación de un tipo de historiografía a una "tradición" filosófica (analítica o continental) no es excluyente.

${ }^{8}$ Hay en realidad un tercer "tipo" de historiografía, la más extendida, a saber, aquella que no se plantea nunca el problema de la metodología en historia de la filosofía ni el problema, íntimamente asociado al primero, de la finalidad de la investigación historiográfica en filosofía. Por lo demás, no podemos dejar de mencionar aquí el importante trabajo de Pablo Oyarzun, El dedo de Diógenes. La anécdota en filosofía, 1996. En dicha obra, Oyarzun discute y redefine las categorías de "historia interna" vs "historia externa" en una reflexión original, que valora a partir del concepto de "anécdota", la obra "doxográfica" de Diógenes Laercio, tan desacreditada por los historiadores de todos los campos. Empero, no discutiré estas ideas, pues, aunque son de suma importancia, me sacarían de mi propósito actual. 
dos órdenes de preguntas (filosóficas e históricas), dicen pertenecer a la "tradición analítica".

Es necesario hacer aquí algunas aclaraciones preliminares: la historiografía del primer tipo tiene algunos presupuestos que, a pesar de que los formula de manera explícita, no se toma, las más de las veces, la molestia de justificar. Estos son: 1) que los "problemas propiamente filosóficos" son trans-históricos e incluso atemporales, por no decir eternos (Mulligan 1997, 64; Glock, 2008, 869); 2) que hay un progreso real en el conocimiento filosófico (Mulligan 1997, 91); 3) que la filosofía vive de su búsqueda de la verdad, empresa superior e independiente del trabajo exegético. La historiografía del segundo tipo tiene también presupuestos, cuya validez, a diferencia de la primera, busca demostrar mediante su ejercicio mismo. Estos son: 1) que los "problemas propiamente filosóficos" son problemas históricamente determinados; ${ }^{9}$ 2) que hay una transformación real de las formas del saber filosófico; 3/ que no hay filosofía sin exégesis filosófica (sin "comentarios") y que, tan importante como la búsqueda de la verdad, es la determinación de las condiciones bajo las cuales una cierta forma discursiva (entre ellas, la búsqueda de la verdad) se vuelve necesaria. Como se ve, en el marco de este nuevo debate entre estos dos tipos de metodología historiográfica, las posiciones parecen irreconciliables, no solo porque las finalidades de cada modo de hacer historia de la filosofía difieren radicalmente, sino también porque parecen tratar sobre objetos completamente distintos. La primera dice de sí misma que es una historiografía "orientada hacia los problemas" filosóficos (Glock 2008, 869), entiéndase hacia los problemas trans-históricos de la filosofía (se suele hablar entonces de "nuestros problemas", universalizando así un modo particular del discurso filosófico contemporáneo). Con ello se pretende, por una parte, legitimar el quehacer historiográfico, por cuanto se halla filosóficamente justificado, $y$, por otra parte, acusar a la segunda no solo de no hacer filosofía, sino también de hacer mala historia. ${ }^{10}$ La segunda, en cambio, acusa a la primera no simplemente de no hacer historia, sino, más profundamente, de "mitologizar" (Skinner 1969) y, por ende, de hacer de la filosofía, como lo quería Borges no sin cierta ironía, una rama de la literatura fantástica. Así las cosas, la disyuntiva que habíamos creído dejar atrás vuelve

${ }^{9}$ Contrariamente a lo que los historiadores "analíticos" pretenden, es completamente falso y absurdo atribuir a los historiadores del segundo tipo la tesis según la cual las preguntas filosóficas, al ser "históricas", no tendrían nada de propiamente filosóficas. Tampoco puede colegirse esto de sus escritos.

${ }^{10}$ Es lo que hace, por ejemplo, Glock en su artículo "Analytic Philosophy and History: A Mismatch?" (2008, 867-897). 
a aparecer y pretende obligarnos a elegir al interior mismo de la disciplina: la "historia de la filosofía" se vuelve historia o filosofía. ${ }^{11}$

En el marco de este debate propondremos, en lo que sigue, una exposición crítica de la posición de la arqueología filosófica tal como ha sido desarrollada en los últimos veinte años por el medievalista y filósofo francés Alain de Libera. ${ }^{12}$ Intentaremos mostrar, en primer lugar, que esta distinción existe; en segundo lugar, cuál es el modo particular de "cientificidad" que puede atribuirse a la historia de la filosofía, en la medida al menos en que procede arqueológicamente; $y$, en tercer lugar, mostraremos en qué sentido dicha distinción es filosóficamente relevante.

\section{FILOSOFÍA E HISTORIA DE LA FILOSOFÍA}

Hay muchas maneras de afirmar una diferencia entre filosofía e historia de la filosofía, pero quizá la más interesante es la que parte por negar la identidad entre ambas. Desde un punto de vista institucional, "filosofía" es habitualmente un término genérico materializado por la división administrativa, al interior de una "facultad", correspondiente al "departamento", mientras

11 Esta disyuntiva acaso traiga a la memoria de alguno aquella en la que se encontrara otrora la historia de la filosofía en Francia, hacia fines del siglo XIX, dividida por dos metodologías: una que hacía recurso a la biografía, la historia de la sociedad, la historia de las religiones (es el caso de un Espinas) y otra que apuntaba hacia la reconstrucción sistemática (como es el caso de un O. Hamelin). Ya Étienne Gilson, a partir de su tesis de 1913, y luego en sus diversas obras, había mostrado la necesidad de un uso combinado de ambas metodologías. Véase al respecto Gouhier 1925, 1-38.

12 Sobre el método arqueológico, consultar De Libera 1999, 479-494; Apel, Barnes y Bellone 2000, 552-587. Estas ideas han sido expuestas más ampliamente en De Libera 2016. El presente trabajo no pretende ser un resumen, sino, como se dijo, una "exposición crítica". Por lo mismo, daré aquí un breve recuento de dos de sus artículos principales dedicados a esta cuestión. En "Le relativisme historique. Théorie des 'complexes questions-réponses' et 'traçabilité'” (1999, 479-494), el autor se centra en la noción collingwoodiana de "complejo de preguntas y respuestas" (CPR), así como en las condiciones de "trazabilidad" de los CPR, es decir, de aquello que permite identificar o distinguir dos CPR dados en momentos históricos distintos. En "Archéologie et reconstruction. Sur la méthode en histoire de la philosophie médiévale." (2000, 561-563), en cambio, el autor busca justificar su "relativismo histórico". El relativismo histórico no consiste en la negación ni de la posibilidad de una continuidad semántica entre el original y la exégesis, es decir, la co-referencialidad o co-extensividad entre un enunciado hallado en el original estudiado y los términos con que este es explicado en una exégesis, ni de la posibilidad de designar lo que se designa en el original por un término $\mathrm{X}$, ya sea con el mismo término $\mathrm{X}$, ya sea con otros términos $y, z \ldots$ que puedan ser co-extensivos, sino en la afirmación de la necesidad del historiador de centrarse en la significación más que en la referencia. La co-referencialidad, es decir la posibilidad de una referencia trans-histórica, es aceptable solo "en un cuerpo de enunciados", que la mayoría de las veces es "de tradiciones múltiples, griegas, árabes y latinas". Por otra parte, también intentaremos dar cuenta de la noción, empleada a partir de Archéologie du sujet (2014a), de "dispositivo textual y teórico" que estudiaremos más abajo. Acerca de De Libera, me permito remitir a mi trabajo: Cortés, 2018, 363-374. 
que la "historia de la filosofía" es considerada como una "disciplina" entre otras ("metafísica", "filosofía moral", "filosofía de la mente", "filosofía política", etc.). Sin embargo, a diferencia de estas otras disciplinas, la "historia de la filosofía" parece no tener objeto propio: un curso de historia de la filosofía puede versar sobre un autor, la obra de un autor, un período (filosofía antigua, medieval, moderna, contemporánea), un período dentro de un campo o de un autor (teoría del conocimiento en la filosofía moderna o en Descartes), etc. La historia de la filosofía se desmarca así de la "filosofía de la historia", entendida como una reflexión filosófica de ese objeto que es la "historia". De aquí viene también la voluntad de muchos académicos de excluir la historia de la filosofía de la filosofía: la historia de la filosofía, se dice, es una disciplina histórica, no filosófica, por cuanto se interesa por los mismos campos que la filosofía (metafísica, filosofía de la mente, filosofía moral, filosofía política) pero como "cosas muertas". La filosofía consiste en hacer metafísica, en hacer filosofía de la mente, en hacer filosofía moral o política, es decir, en enfrentarse a objetos tales como la "realidad", el "ser", la "mente", la "verdad" o la "obligación moral”, a partir de problemas filosóficos que gozan de una vida propia (Mulligan 1997, 64, 78). El problema de la relación entre filosofía e historia de la filosofía pareciera entonces deber plantearse en términos de "interés": ¿Cuál es el interés "propiamente filosófico" de estudiar la historia de lo que fue filosófico? Con esta pregunta se pretende dar una estocada mortal a las pretensiones filosóficas de aquel que se interese por la historia de la filosofía.

En efecto, lo anterior implica que se supone, como un hecho de suyo evidente, la existencia, independiente de toda historicidad, de un complejo de preguntas (filosóficas) relativas a un cierto objeto (filosófico) y un complejo de respuestas (filosóficas) a esas preguntas que determinan una posición (filosófica) relativa a dicho objeto, preguntas y respuestas con las que un filósofo debe lidiar de manera exclusivamente argumentativa. Al contrario, al no disponer de objeto propio, la historia de la filosofía no puede tampoco disponer de preguntas ni de respuestas propias, es decir, no tiene nada de lo que constituye a una disciplina como tal. De esta manera, pareciera que las opciones para la historia de la filosofía se reducen a dos: o bien, asume, si quiere permanecer en el departamento de filosofía, su rol ancilar respecto de las disciplinas propiamente filosóficas, es decir que su función se restringiría a una "propedéutica" para las mismas. Así, el historiador de la filosofía deberá conformarse a la ley de la filosofía según la cual un verdadero filósofo sólo se interesa por problemas filosóficos vivos, a cuya solución su estudio deberá aportar. 0 bien, se exilia en algún otro departamento, de preferencia 
el de historia, donde, bajo la forma de la "historia de las ideas" (de preferencia las "ideas políticas") pueda ser ejercida legítimamente.

Lo primero que hay que criticar es, entonces, este falso parecer: la historia de la filosofía es una disciplina propiamente filosófica, puesto que su objeto, sus preguntas y sus respuestas son propiamente filosóficas. De manera general, la historia de la filosofía se ocupa de una diversidad de ítems filosóficos: problemas (como el "problema de los universales"); doctrinas (como el "hilemorfismo", el "contractualismo", etc.); conceptos (como el de "materia", o el de "acto"); tesis (como el "nominalismo" o el "realismo"); abocándose, por lo general, a un período de la historia (antigua, medieval, moderna...), o al paso de un período a otro, o a la obra de algún autor. Dado su procedimiento crítico, el historiador se ve también confrontado, aunque con menor frecuencia, a cuestiones que son, prima facie, ajenas a la filosofía: así los problemas historiográficos de "periodización" (v.gr., la legitimidad de divisiones históricas como "Antigüedad", "Edad Media” y "Modernidad") o los de categorización doctrinal (v.gr., la validez de una categoría como la de "racionalismo" o la de "empirismo"), o la historia de las instituciones universitarias, de las legislaciones relativas a la producción del saber: el estudio de este tipo de objetos es fundamental desde el punto de vista arqueológico. Esto bastaría, dicho sea de paso, para desmarcar al historiador de la filosofía del historiador propiamente dicho: la historia de la filosofía es un trabajo para el que el historiador, por muy erudito que sea en el campo de la filosofía, no es apto, y es una disciplina con la que, como la lógica o las lenguas clásicas, todo estudiante de filosofía debiera verse confrontado durante su formación. ${ }^{13}$

Como acabamos de decir, el "objeto" de la historia de la filosofía está constituido de ciertos ítems: problemas, conceptos, doctrinas, tesis, principios, axiomas, reglas lógicas, esquemas conceptuales, etc. Los llamaremos aquí "elementos del discurso filosófico", en el sentido en que no hay discurso filosófico que no disponga de dichos elementos. En relación con esto, podemos decir que, de manera muy general, todo historiador de la filosofía se pregunta respecto de dichos elementos: ¿Cómo se puede llegar a pensar $a, b$ o $c$ ? ¿Cómo se llega a tal problema $a$, a tal concepto $b$, a tal doctrina $c$, etc. ${ }^{14}$

13 No digo por cierto que la filosofía concierna exclusivamente a los profesores de filosofía ni que los profesores de filosofía sean los únicos aptos a hacer filosofía. Lo único que digo es que se requiere de una formación disciplinar para hacer filosofía, que puede ser obtenida dentro o fuera de un departamento de filosofía, por cuanto considero que la filosofía es una formación discursiva cultural y no, como pretendía Tennemann, el movimiento reflexivo de un instinto de la razón. Ver Tenneman 1829, 3.

14 Cuando más arriba hablé de la "finalidad" de cada tipo historiográfico, no me refería al hecho de responder a esa pregunta (común), sino, más bien, al fin al que cada historia se ordena cuando responde a dicha pregunta. Por ejemplo, la historiografía analítica de la 
Esto significa que la tarea de un historiador de la filosofía consiste en dar cuenta de $a, b$ o $c$. Ahora bien, hay varias maneras de responder a esta pregunta. Precisamente, los dos tipos extremos de metodologías opuestas distinguidos más arriba constituyen las dos respuestas extremas opuestas posibles: uno, que hace énfasis en la historicidad del proceso por el que se llega a $a, b$ o $c$; el otro, que hace énfasis en la argumentatividad del proceso por el que se llega a $a, b$, o $c$. Por supuesto, como veremos más en detalle con respecto a la arqueología, el que se haga énfasis en uno u otro carácter del proceso no quiere decir que se excluya completamente el otro: ambos tipos contienen rasgos del tipo opuesto. Ahora bien, ¿por qué la pregunta sobre el "proceso" por el que se llega a pensar un "elemento" filosófico es filosófica? Dicho de otra forma, ¿cuál es el interés filosófico en estudiar historia de la filosofía? 0, si se prefiere, ¿la historia de la filosofía puede enseñarnos algo filosófico acerca de la filosofía? Lo primero que uno podría decir al respecto es que con el estudio de autores se enseña a pensar filosóficamente. Sin embargo, el aspecto pedagógico, si bien me parece fundamental, no es lo único en juego, ni siquiera lo más importante. En efecto, en el debate abierto entre estas dos historiografías filosóficas, lo que está en juego es la naturaleza misma de los elementos constitutivos del discurso filosófico: ¿cuál es el modo de existencia de los conceptos, problemas, doctrinas, axiomas, etc., en filosofía? La historia de la filosofía es por tanto una disciplina cuya interrogación última atañe a la naturaleza de la filosofía, pregunta reflexiva entonces que, a nuestro parecer al menos, no puede sino ser fundamentalmente filosófica.

La "arqueología filosófica" o "conceptual" es, ante todo, un método del que dispone el historiador de la filosofía para enfrentarse a su objeto de estudio, método que hace énfasis en la historicidad de los procesos argumentativos por los que se llega a $a, b$ o $c$. La finalidad que orienta todo el trabajo historiográfico del filósofo arqueólogo fue claramente definida por Foucault: se trata de determinar "aquello que hace que una cierta forma de pensamiento se vuelva necesaria" $(1994,221)$. En términos de A. de Libera, la labor de todo historiador de la filosofía consiste en "determinar aquello que conduce al pensamiento filosófico a sí mismo", esto es, dicho en términos heideggerianos, "aquello que llama a pensar" (De Libera 2000, 584). Sin embargo, la comunidad de proyecto no impide que haya ciertas diferencias no-

filosofía busca determinar la verdad o falsedad de una tesis-posición y a partir del análisis de los argumentos que la sostienen relativamente a una pregunta acerca de tal o cual objeto. El interés de este tipo de historiografía por dichas tesis y argumentos proviene del hecho de que considera que tanto el objeto como la pregunta son actuales, es decir, son asuntos por los que la filosofía se interesa en la actualidad. 
tables entre la "arqueología filosófica" propuesta por Alain de Libera y la arqueología de tipo foucaultiano. En efecto, mientras que esta rehúye de la "historia de la filosofía" como disciplina, la primera se centra precisamente en aquellos discursos que han constituido históricamente dicha disciplina. Esto no quita, por cierto, que la arqueología filosófica comparta de hecho con la arqueología foucaultiana el proyecto de una "historia crítica del pensamiento", para lo cual articula instrumentos de análisis de índole diversa como son el análisis filosófico y el estudio histórico. En el caso de la arqueología filosófica de estilo deliberano, el estudio histórico se centra en la historia de los corpus, de su constitución, de sus diferentes ediciones (la ecdótica), variantes y traducciones. Todo ello es parte constitutiva de la arqueología filosófica, pues la historia del soporte material que sirviera de vehículo para un objeto filosófico dado es lo que permite leer un texto filosófico medieval con los ojos de un filósofo medieval, y por tanto, de entenderlo bajo las condiciones en que los hubiese entendido un filósofo medieval. ${ }^{15}$ De igual modo, es fundamental el estudio de la historia de las instituciones (universidades, escuelas-catedrales, centros de investigación científica, laboratorios, etc.) en las que estos corpus han sido recibidos o constituidos, editados, traducidos, leídos y comentados, por cuanto permite entender la importancia fundamental de las migraciones conceptuales de dichos principios y esquemas para la constitución de un discurso filosófico. ${ }^{16}$ Todo lo anterior, conforme a una exigencia sobre la que Foucault insiste y que consiste en sacar a la luz las discontinuidades a un mismo tiempo históricas y epistémicas que atraviesan y deforman los "objetos filosóficos". Con ello se busca evidenciar las disconformidades que revelan la historicidad de dichos discursos filosóficos contra las pseudo-continuidades que tienden a hacer de su objeto de estudio una entidad trans-histórica, si no an-histórica e incluso "eterna" (Foucault, 1969, 31-43). ${ }^{17}$

Con lo anterior, queremos insistir en dos aspectos relativos a la arqueología filosófica: en primer lugar, que, al afirmarse como un método entre otros, se reconoce también que la historia de la filosofía, como disciplina, dispone no de uno sino de varios métodos diferentes para comprender su(s) objeto(s), y esto en orden a la finalidad que se da a sí misma -aunque también, está claro, puede no tener ningún método, perdiendo entonces todo

15 Consultar De Libera 1999, 479-494, y 2000, 552-587. Es el propio A. de Libera quien distingue su "estilo" de arqueología de la arqueología foucaultiana.

16 Consultar De Libera 2016.

17 Como es sabido, con ello Foucault se opone y crítica la tesis continuista propia de la "historia de las ideas", tal como es concebida por A. Lovejoy (1983, 10-32). Es de notar que Skinner, siguiendo el camino abierto por Collingwood, desarrolló una "historia intelectual" que se distancia críticamente de la "historia de las ideas" promovida por Lovejoy y sus seguidores; consultar, en particular, Skinner 1969, 3-53. 
interés filosófico. En segundo lugar, que, desde el punto de vista arqueológico, el objeto de la historia de la filosofía no es nunca inmediatamente dado a una "experiencia ingenua" o una "intuición", sino que debe ser reconstruido en su historicidad. Esto significa que las reconstrucciones de argumentos o de tesis, al no dejarse asir sin resistencia al análisis puramente conceptual (según las herramientas conceptuales de que dispone la filosofía contemporánea), requieren de una reconstrucción propiamente histórica. Es necesario determinar tanto las condiciones bajo las cuales una tesis sobre un objeto se vuelve significante, como aquellas bajo las cuales el objeto mismo se vuelve un referente posible para el análisis filosófico, condiciones que varían históricamente y que disuelven la "identidad" o la "esencia eterna" del objeto. ${ }^{18}$ Evidenciar las discontinuidades epistémicas equivale a mostrar que, bajo lo que se considera como "El problema de los universales", como si se tratara de un solo y mismo Problema desde Platón hasta hoy, se esconde una serie de problemas disímiles que deben ser reconstruidos cada uno por sí mismo; ${ }^{19}$ equivale a mostrar que bajo lo que se considera como "La subjetividad", como si se tratara de un mismo objeto desde Platón hasta hoy, hay una serie de referentes objetuales diversos que deben ser reconstruidos cada uno por sí mismo; ${ }^{20}$ etc. Esto se hace poniendo de manifiesto las condiciones epistémicas, es decir, los a priori históricos de cada problema, de cada objeto, de cada tesis, de cada concepto, etc. La necesidad de estas reconstrucciones histórico-epistémicas no reside simplemente en el hecho de que, de otro modo, lo que se tiene por "conocimiento" de un problema o tesis de un autor u obra del pasado no tiene referencia alguna y es,

\footnotetext{
${ }^{18}$ No todo método en historia de la filosofía de orientación "analítica" supone una posición "platonizante" respecto de los contenidos de las proposiciones. En particular, hay que señalar el "método reconstructivo", declaradamente nominalista, propuesto por Claude Panaccio $(1994,176)$, consistente en una "traducción en el lenguaje del informante" (i.e. del filósofo analítico) del contenido original. Sin embargo, nominalista o realista, la historiografía de corte analítico tiene una finalidad común: hay tesis filosóficas, sostenidas por argumentos, y dichas tesis pueden y deben ser evaluadas según su verdad o falsedad. Esta finalidad tiene también un presupuesto común: que el marco de validez (el "complejo de preguntas y respuestas") de una tesis del pasado es conmensurable al nuestro (De Libera 1992, 149) - para una panorámica del debate, ver: Castello Dubra 2010, 195-244. Agradezco a los profesores Panaccio y Castello Dubra, quienes gentilmente me hicieron llegar una copia de sus respectivos trabajos.

${ }^{19}$ Consultar: De Libera 2014b. En "Archéologie et reconstruction. Sur la méthode en histoire de la philosophie médiévale." (2000,568). De Libera insiste en que, "para hacer historia", es necesario "reconstituir y describir" la "serie de problemáticas" disímiles que son denominadas exteriormente por un mismo término (una vez más "el" problema de los universales consistente, en realidad, en una serie de problemas histórica y epistémicamente disímiles), es decir, de "reconstruirlas".

20 Consultar: De Libera 2007; De Libera 2014a.
} 
por lo tanto, del orden de la ficción o del mito (por cuanto se cree en la verdad de lo que se narra), sino que, además, porque de otro modo se falsea por completo la naturaleza de los problemas, tesis o conceptos filosóficos.

Al hacer énfasis en la determinación de los a priori históricos, lo que pretendo es poner de manifiesto una particularidad de la arqueología filosófica, a saber, que no es un estudio de algo que sea externo a la filosofía: las circunstancias históricas, económicas, políticas, importan única y exclusivamente en la medida en que facilitan la comprensión de un problema o tesis filosófica. Por ejemplo, el problema de los dos sujetos del pensamiento y las tesis del averroísmo y del anti-averroísmo aparecen durante el siglo XIII en occidente latino gracias, principalmente, a la introducción del corpus completo de Aristóteles acompañado de los comentarios de Averroes. Evidentemente, ningún historiador de la filosofía dirá que el problema noético de los dos sujetos se entiende, en sí mismo, por tal o cual circunstancia histórica. Lo único que afirma es que, sin la introducción en occidente latino de las obras de Aristóteles y de los comentarios de Averroes, la noética no hubiese conocido ni ese problema ni las tesis que sobre él se determinan. Dicho de otro modo, simplemente no habría existido el problema de los dos sujetos del pensamiento. Tampoco sin los equipos de traductores de Toledo ni sin aquella universitas magistrorum et scolarium que, a comienzos del siglo XIII en París, obtuvo los estatutos que la constituirían en una institución autónoma de producción y transmisión del saber que será conocida luego con el nombre de "universidad"21. Por el contrario, si dichas circunstancias son obviadas, el historiador será conducido a producir una mitología acerca del problema, creyendo ver dicho problema ya en Averroes ${ }^{22}$ mismo o incluso en Aristóteles.

De acuerdo con esto, los a priori históricos serán aquellos principios que definirán una episteme, es decir, las "condiciones de realidad de los enunciados" (Foucault 1969, 167), condiciones que determinan la aparición (émergence) de los enunciados en un "discurso" (campo de enunciación) históricamente dado. ${ }^{23}$ Es sobre este campo de determinaciones epistémicas que puede ser restituido o reconstruido el "complejo de preguntas y respuestas" (CPR) al interior del cual un enunciado filosófico adquiere sentido

${ }^{21}$ Consultar: Halphen 1931, 221. De Libera apunta a la especificidad de la universidad frente a otras instituciones de producción de saber de la época (2004, 367-376).

22 Jean-Baptiste Brenet $(2005,53-86)$ ha mostrado de manera convincente que no hay una "teoría de los dos sujetos del pensamiento" en Averroes, si por ella hay que entender una doble atribución de la intelección a dos sujetos de inherencia distintos. Esta es una invención propiamente latina, más precisamente una tesis que el anti-averroísmo atribuye a Averroes y a los averroístas latinos.

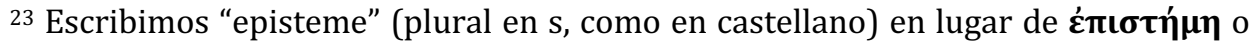
epistếmē, por cuanto se trata de un concepto filosófico, y no de la palabra griega. 
(Collingwood 1939, 31-32). ${ }^{24}$ De este modo, como se ve, Alain de Libera articula las herramientas de análisis propias a la arqueología de Foucault a la "lógica de preguntas y respuestas" de Collingwood. En efecto, el primer y más próximo sistema de relaciones conceptuales que determina a todo enunciado es el CPR al que pertenece, complejo al interior del cual solamente cabe analizar lógicamente el enunciado (i.e., determinar si es "contradictorio" o no, si es verdadero o falso, etc.). ${ }^{25}$ Sin embargo, una vez determinado lo que podemos llamar el "contexto lógico" del enunciado (i.e., el CPR), es necesario describir la episteme, que cumple la función de lo que Collingwood llama un "presupuesto absoluto", 26 en el sentido en que la episteme es un complejo de enunciados inmediatamente asumidos como principios o axiomas que da origen a una pregunta (o una serie de preguntas), engendrando así un CPR, esto es, un conocimiento.

El estudio de la historia del soporte material hace posible un estudio pormenorizado de la historia de las variaciones formales que determinan un discurso. En este marco, el verdadero problema al que se ve confrontado el filósofo arqueólogo es la explicación del paso de un complejo de preguntas y respuestas a otro, es decir, la explicación de lo que llamábamos más arriba las discontinuidades histórico-epistémicas. Conforme a una exigencia declarada de manera explícita por Foucault, la arqueología deliberana se propone determinar las "reglas de paso" que permiten dar cuenta de la transformación de una episteme en otra. Uno de los síntomas más evidentes de que estamos en presencia de dos epistemes diferentes lo proporciona la comparación de dos CPR, comparación hecha a partir de lo que se considera (al menos como suposición heurística del filósofo arqueólogo) como un mismo objeto. No cabe aquí reproducir el esquema propuesto por Alain de Libera en vistas a una "descripción lógica de las transiciones" por las que un CPR deviene otro. ${ }^{27}$ Bástenos señalar que es por el juego de las similitudes y de las diferencias entre un CPR que se encuentra en un momento T1 y otro encontrado en un momento T2 relativo a un "mismo objeto" (a lo que nuestra visión retrospectiva identifica, prima facie, como un mismo objeto ${ }^{28}$ ) que se

${ }^{24}$ De Libera señala justamente que este método es particularmente propicio para el estudio de la filosofía y de la teología medieval, por cuanto estas disciplinas procedían precisamente a partir de preguntas (las quaestiones) bien definidas.

25 Consultar: Collingwood 1939, 33.

26 Consultar: Collingwood 1940, 21 y ss.

27 El texto se halla en "Le relativisme historique. Théorie des 'complexes questionsréponses' et 'traçabilité"”, (1999, 489-490). Se trata de la "tesis 5" por la que A. de Libera busca dar cuenta de su "relativismo histórico" de corte collingwoodiano.

28 La crítica a la "visión retrospectiva", tal como es formulada por Bergson, es una constante de la historiografía francesa del siglo 20. Para la recuperación de esta crítica en el marco del proyecto arqueológico, ver De Libera 2014b, 26-28. 
podrá determinar el eventual cambio de episteme. Una regla de transformación debe entonces entenderse como aquello cuya presencia o cuya ausencia determina una serie de preguntas posibles y una serie de respuestas posibles, es decir, una serie de enunciados de distinta índole realmente efectuados que "hablan de una misma cosa". Es también lo que Alain de Libera llama un "dispositivo textual y conceptual" que se halla efectivamente, como parte integrante, en el "archivo" constitutivo de la investigación arqueológica. ${ }^{29}$ Entendemos la relación establecida entre el dispositivo y el archivo como una relación de ejecución: el dispositivo es precisamente lo que hace que la ley del archivo se cumpla, que el sistema rija efectivamente la aparición de los enunciados, su enunciabilidad, su funcionamiento y su modo de actualidad. Alain de Libera ha dado varios ejemplos de dichos dispositivos: para la descripción de la génesis y estructura del "problema de los universales" (De Libera 2014b), del "problema del ser" (2000, 572, 580), del "problema de la subjetividad" (2007; 2008; 2014a). Sería absurdo intentar resumir aquí estas inquisiciones; bástenos decir que, para cada una de ellas, el trabajo consistió en establecer la historia del corpus (de enunciados), ya sea por una serie de "quiasmos" (2007; 2008; 2014a, 76-79), ya sea por "sobre-impresiones" recurrentes $(2000,574)$; y en describir la red de preguntas, tesis y conceptos que estos "vehiculan" $(2000,582)$. Así, gracias, por una parte, a esta doble pertenencia de todo enunciado a una episteme y a un complejo de preguntas y respuestas, $\mathrm{y}$, por otra parte, a la atención dada a la historia de los corpus en el marco de la "larga duración", la arqueología filosófica de estilo deliberano asume, de manera explícita, el relativismo histórico, el holismo epistemológico y el discontinuismo -consecuencias (y no presupuestos) de las exigencias de la investigación historiográfica. ${ }^{30}$

${ }^{29}$ Consultar: Michel Foucault 1969, 170-171. El archivo es "en primer lugar la LEY DE LO QUE PUEDE SER DICHO, el sistema que rige la aparición de los enunciados como acontecimientos singulares [...]; es lo que, en la raíz misma del enunciado-acontecimiento, y en el cuerpo en el que se da, define de entrada el sistema de su enunciabilidad; [...] es lo que define el modo de actualidad del enunciado-cosa; es el sistema de su funcionamiento; [...] es lo que diferencia a los discursos en su existencia múltiple y los especifica en su duración propia" (citado por De Libera 2016, 22).

30 "Nuestro relativismo histórico consiste en la afirmación que toda tesis es para nosotros relativa al mundo que la vio nacer, el cual la reclama, a su vez, para ser mundo. Toda tesis filosófica es la tesis de un mundo. El relativismo, correctamente entendido, es holista, y por esta razón, es también discontinuista" (De Libera 1992, 150); "La concepción que defiendo en historia de la filosofía medieval es relativista, holista y discontinuista" (De Libera 1999, 482). El relativismo histórico así definido no deja de recordar la concepción que Juan Emar tenía de la relatividad: "La relatividad se hace muchas veces sinónimo de arbitrariedad, de inconsistencia, de néant. Es esa idea que rebato. La relatividad indica cambio, transformación continua, pero fija, al mismo tiempo, la ley absoluta para cada 'caso', ley que pasa a ser relativa sólo en otro caso, y como un caso $\mathrm{X}$ puede durar un segundo como millones de años [...] y abarcar tanto < una relación entre dos cosas $>$ como millones de veces más <se 
Ahora bien, dos preguntas surgen inevitablemente acerca de dicho procedimiento: una relativa a las posibilidades propiamente filosóficas que este abre al interior del debate actual en filosofía. ¿Qué utilidad tiene para nosotros el estudio de, por ejemplo, el problema de los dos sujetos del pensamiento en los términos en que se planteó para la escolástica de los siglos XIII y XIV? La otra pregunta atañe a la cientificidad de la historia de la filosofía. En efecto, dicha metodología no parece tener en cuenta que el historiador se halla también en una episteme dada, concernido por un complejo de preguntas y respuestas, que lo determinan necesariamente a la hora de interesarse por el pasado de la filosofía. De suerte que todo historiador parece condenado a una retrospección que deforma inevitablemente el conocimiento que pueda tener del objeto estudiado. ¿Cuál es entonces la objetividad que el conocimiento de la historia de la filosofía puede alcanzar? ¿Es la retrospección una condena del proceder historiográfico?

\section{CIENTIFICIDADES DE LA FILOSOFÍA}

Se acusa periódicamente a la historia de la filosofía de no ser científica, de ser incapaz de acomodarse a los criterios de la investigación científica. Al parecer, esta es la razón por la que se le da ese estatuto de ancilla philosophiae o de mera propedéutica para la verdadera filosofía, que es la que ha sabido adaptarse a los (ya no tan) nuevos tiempos del dominio de las "ciencias duras". Sin embargo, esto implica presuponer que toda cientificidad debe acomodarse a un mismo orden (o "modelo") de cientificidad, el orden de las ciencias "de la naturaleza". Contrariamente a lo anterior, consideramos que la filosofía en general no está obligada a plegarse al modelo de las ciencias naturales para ser científica, y que cada disciplina filosófica particular puede reclamar legítimamente un orden de cientificidad propio. ${ }^{31}$ Lo anterior es posible si entendemos por ciencia el procedimiento por el cual se elabora una hipótesis explicativa para un hecho que, en un campo disciplinar dado, engendra un cuestionamiento, explicación que se establece a través de argumentos, de suerte que se produzca un conocimiento certero: es decir,

termina> llegando a leyes absolutamente fijas" (Emar 2014, 81-82), pero que rigen a esas cosas durante un tiempo $\mathrm{T}$ determinado, así sea de millones de años.

31 Con esto no queremos decir que la filosofía tenga el mismo "rendimiento" que las ciencias de la naturaleza. Es claro que esto no es así. La filosofía se caracteriza por su evidente inutilidad económica, política o moral (entendidos estos no como saberes, sino como fórmulas de obediencia al triple orden del Trabajo, del Estado y de la Familia). El problema parece estar en la desproporción entre la labor, es decir, el tiempo y el gasto energético, requerido por el filósofo para llegar a sus fines y la necesidad en la que se ve de publicar sus "resultados", por cuanto estos son el único "valor de cambio" del que dispone para enfrentarse al mercado laboral. 
proponer una respuesta correcta a una pregunta disciplinar válida. ${ }^{32}$ Decir que la historia está condenada a la "acientificidad" por el hecho de que no puede aplicársele el método experimental es, desde este punto de vista, confundir órdenes de cientificidad muy diversos. El orden de cientificidad de la historia de la filosofía depende del campo disciplinar al que pertenece. Así, si por filosofía entendemos aquel conjunto de discursos que se rige por una doble exigencia: ${ }^{33}$ 1) que permite conocer -cualquiera sea el significado que se dé a esta palabra- el objeto de que trata y 2) que establece una reflexión crítica acerca de los presupuestos que dicho conocimiento implica, entonces, la historia de la filosofía, en la medida en que responde a estas dos exigencias, es un discurso filosófico, discurso que responde, por lo demás, al orden de cientificidad de la filosofía. En efecto, la historia de la filosofía consiste en una investigación científica propiamente dicha, por cuanto requiere de una indagación acerca de los elementos del discurso filosófico, indagación a la vez material y conceptual, con el fin de esclarecer las presuposiciones que determinan al discurso filosófico y que lo han llevado a ser ese discurso y no otro. Si "conocer" consiste en hallar "leyes", la arqueología propone un tipo particular, a saber, precisamente, las "reglas de transformación", las que, si bien no son "eternas" y ni siquiera trans-históricas, sino, por el contrario, codependientes del momento cuya realidad posibilitan, no por ello no permiten una verdadera explicación. Ahora bien, ¿de qué tipo es esta explicación?

Se plantean al menos dos preguntas relativas al modo explicativo de la historia de la filosofía. En efecto, el requisito mínimo para hablar de "historia" es que haya un relato. ${ }^{34}$ Ahora bien, el relato parece oponerse al argumento, ${ }^{35}$ necesario este último para toda explicación científica. Así, la primera pregunta que debiéramos hacernos es: ¿En qué medida un "relato" es efectivamente explicativo? La segunda pregunta se plantea porque toda investigación histórica parece estar condenada a la proyección retrospectiva

32 Consultar: Collingwood 2010, 68. La definición que damos aquí de la "ciencia" es más descriptiva que normativa. Lo importante, a juicio nuestro, es que, si una definición de la ciencia quiere ser "normativa", ella no puede olvidar la realidad que pretende normar. Al respecto, parece razonable creer que, como escribe Michel Serres: "Un saber sin ilusión es una pura ilusión en la que todo se pierde, incluso el saber. Se trata de algo así como de un teorema: el único mito puro es el <mito> del saber puro, es decir, exento de todo mito. No conozco otros, tan llenos de saber están los mitos y tan lleno de sueños e ilusiones, el saber" (1974, 259). La traducción es nuestra.

33 Como parece haber sido el caso de la "metafísica", entendida no como una ontología, sino como una ciencia de los presupuestos (tà prôta kaì tà aítia, Aristóteles, Metafísica, I, 2, 982 b 2) del conocimiento de los objetos físicos.

${ }^{34}$ Retomamos la definición de Paul Veyne: la historia es el relato de acontecimientos reales que tienen al hombre por actor $(1979,13)$. Si su objeto no es otro que aquellos acontecimientos, su finalidad está en el conocimiento verdadero de las acciones humanas que produjeron dicho acontecimiento.

35 Retomamos aquí la distinción establecida por Panaccio (1994). 
de los presupuestos del historiador en el archivo por él estudiado. Ahora bien, la retrospección es, como lo señalara ya Skinner (1969), uno de los modos de mitificación más comunes del relato histórico. De suerte que parece necesario preguntar: ¿En qué medida la cientificidad de la explicación histórica puede entonces escapar al mito?

1) El tipo de conclusiones que un historiador saca de la reconstrucción narrativa de la historia depende evidentemente tanto de los instrumentos de que dispone el historiador para trabajar su material como de la materia acerca de la cual se propone en primer lugar establecer la narración. Digamos por ejemplo que el historiador se propone establecer la historia de la metafísica en el siglo XIII. Si dicho historiador a) desconoce que hasta mediados del siglo XII, sólo se conoce de Aristóteles las Categorías y una parte del De interpretatione, traducidos al latín por Boecio en el siglo VI, y mediados por a.1) la traducción que el mismo Boecio hizo de la Isagoge de Porfirio y a.2) el uso que Boecio dio a la lógica aristotélica, a saber, un uso teológico de la atribución categorial (la praedicatio in divinis); y b) si desconoce que durante el siglo XIII se procedió en el occidente latino a la traducción y al comentario del corpus completo de Aristóteles (el que incluía de hecho textos apócrifos, como la Teología de Aristóteles o el Liber de causis, textos neoplatónicos, etc.), traducciones y comentarios que se vieron mediados por las traducciones y los comentarios árabes (de Al Farabi, Ibn Sina, Ibn Rushd, algunos de los cuales, como es el caso de la Metafísica de Avicena, fueron traducidos y comentados antes que las obras del Filósofo); esto es: si desconoce dos hechos fundamentales de la historia de los corpus de Aristóteles, será incapaz de distinguir que hay al menos dos Aristóteles distintos, uno anterior y otro posterior al siglo XII, a cada uno de los cuales se le atribuirán dos ontologías completamente diferentes (De Libera 1999, 579-580).

Por ello, la materia prima del historiador de la filosofía no está ni debe estar inmediatamente constituida por las ideas, ni por los argumentos, sino por los corpus. La historia de los corpus delimita de suyo el complejo de preguntas a las que las tesis (ideas) filosóficas responden y da sentido a los argumentos que las sostienen. En la medida en que debe ser la materia la que decide cuáles son las herramientas apropiadas para su tratamiento, las herramientas básicas del historiador de la filosofía serán aquellas proporcionadas por la filología (entendida como técnica de reconstrucción, fijación e interpretación de los textos). Es claro, sin embargo, que esto no basta para hacer una "historia filosofante de la filosofía", pero sí es una condición necesaria, si lo que se pretende es tener un conocimiento cierto acerca de aquello de que se habla en un horizonte epistémico del pasado de la filosofía. Es además imprescindible establecer, sobre la historia de los corpus y delimitada 
por ella, una historia de las redes de problemas, de tesis, de conceptos y de argumentos. El relato histórico se vuelve narración propiamente explicativa en la medida en que articula estas dos historias. De este modo, una historia filosofante de la filosofía no es necesariamente una historia idealista de la filosofía, es decir, una historia sin tiempo o, más bien, sin devenir. ${ }^{36}$ Es plenamente posible y deseable hacer historia filosofante de la filosofía tomando en cuenta (y en serio) la materialidad de los enunciados filosóficos, por cuanto devela en última instancia los a priori históricos en tanto que dispositivos textuales y conceptuales que operan como presupuestos absolutos de todo enunciado posible, es decir, como "aquello que hace que acontezca lo que acontece, y que, en tanto tal, él mismo no acontece" (De Libera 2014a, 26), sin que por ello deje de ser histórico.

2) Examinemos ahora la segunda pregunta, a saber, si es posible escapar a la "visión retrospectiva", pregunta importante por cuanto esto parece una condición de cientificidad para la historia. Para responder cabe hacerse otras preguntas, que la preceden lógicamente. Primero: ¿Es verdad que al estudiar las obras del pasado estamos inevitablemente determinados por nuestro presente, es decir, por nuestros intereses y nuestras categorías, a comprender el pasado? De ser así: incluso si se acepta que es algo que impide la cientificidad, ¿es algo de lo que necesariamente conviene escapar? Estas preguntas se plantean por cuanto pareciera que, para el historiador analítico, la visión retrospectiva, lejos de ser aquel obstáculo epistemológico al que el historiador de la filosofía debería confrontarse, es el beneficio de su situación privilegiada al encontrarse en la cima del progreso. A la primera pregunta habría que dar una doble respuesta: la primera es que, efectivamente, el historiador sólo puede interrogar el pasado a partir de problemas que surgen en su propio presente. Una interrogación del pasado sin problemas no es una interrogación, no pasa de ser una suerte de coleccionismo estéril o de "historia de anticuario" (para retomar la categoría de Nietzsche). Esta exigencia es de hecho explícitamente formulada por Collingwood (1939, 124-125) y retomada por Alain de Libera; en ningún caso es un privilegio del "historiador analítico", como lo creen no sin fervor estos mismos historiadores analíticos. ${ }^{37}$ La diferencia entre una y otra orientación no re-

36 Una historia idealista de la filosofía es aquella para la cual las ideas y los argumentos flotan en un cielo etéreo; desde este punto de vista, su objetivo consistiría en narrar cómo las ideas y los argumentos son ejemplificados en la historia bajo tales y tales términos, pero que, en substancia, serían los mismos.

37 Consultar: Mulligan 1997, 78; Glock 2008, 869. Esta creencia probablemente les venga menos de una mala fe que de una mala metodología. Al ser sus problemas los únicos problemas verdaderamente filosóficos, todo problema que no cuadre con los suyos, no podrá ser percibido como tal. 
side simplemente en la naturaleza que cada uno de ellos atribuye a los problemas filosóficos, trans-históricos para uno, históricos para el otro, sino, más profundamente, en lo que cada uno de ellos busca al interrogar el texto guiado por tales preguntas. El historiador arqueólogo de la filosofía no pretende hacer que el texto filosófico del pasado responda a su problema, pues sabe que no puede dar tal respuesta. Sus preguntas lo orientan en la descripción del proceso de pensamiento que pretende dar. El historiador analítico tortura al texto para extraer de él una respuesta ("reconstruida") a su problema. Es entonces el modo de inquirir el texto de uno y otro historiador lo que decide cuáles serán las respuestas que se den a las preguntas sobre la retrospección.

Con esto pasamos a la segunda respuesta: si bien estamos determinados a interrogar el pasado a partir de nuestro presente (o, en palabras de Borges, estamos condenados a "ser actuales"), no estamos necesariamente determinados a ceder a la tendencia de atribuir a textos del pasado problemas, categorías, objetos conceptuales y sobre todo respuestas que pertenecen a nuestro horizonte epistémico. En efecto, la historia arqueológica de la filosofía no busca sancionar las tesis del pasado sino, en primer lugar, dar espacio a una comprensión del enunciado filosófico pretérito. ${ }^{38}$ Esto es lo que prima en una arqueología, antes que el uso o rendimiento que se pueda sacar (o más bien, que se cree poder sacar) de dicho enunciado en el debate filosófico actual. Es necesario determinar primero "aquello de que se hablaba" para poder saber qué era "lo que se decía" sobre aquello. Existe la posibilidad de que algún autor o texto del pasado hablara de lo mismo que en la actualidad se habla. Sobre todo, como se anotó más arriba, sería irrisorio negar la existencia de una continuidad semántica, es decir, de una co-referencialidad y co-extensividad presupuesta por todo enunciado del tipo "A dice que $p$ " ( $\mathrm{A}=$ autor del pasado y $p$ un enunciado que el historiador atribuye a A), y que hace posible la traducción en "nuestro" lenguaje filosófico, pues esto condenaría al historiador a la imposibilidad de hablar de lo que fuera del pasado (De Libera 2000, 561). Sin embargo, aunque esto sea así, es absurdo exigir que lo dicho por un autor o texto sobre un tema determinado responda a una pregunta que él nunca formuló.

A partir de lo anterior, es posible responder a la segunda pregunta, relativa a la necesidad en la que se vería el historiador de escapar a la visión

${ }^{38}$ Lo que no quiere decir por cierto que, en consecuencia, la historia de la filosofía se condene a un saber de anticuario, a una erudición estéril. Volveré en la próxima sección al objetivo final de toda arqueología señalado más arriba, a saber, el conocimiento de aquello que nos ha determinado a pensar como pensamos y no de otra forma. 
retrospectiva. Se puede argumentar que, al menos en lo que refiere al historiador que practica el método arqueológico, es imprescindible hacer un esfuerzo por evitar y, si es posible, escapar de las consecuencias de la retrospección. Acaso la peor de estas consecuencias sea precisamente la falta de toda crítica de la "situación" en la que se encuentra el historiador de la filosofía y la pretensión a universalizar sus propios valores (valores, empero, que el historiador es llevado a asumir por dicha situación). Cabe recordar aquí las palabras de Skinner:

There is a tendency [...] to suppose that the best, and not merely the inescapable, vantage point from which to survey the ideas of the past must be that of our present situation, because it is by definition the most highly evolved. Such a claim cannot survive a recognition of the fact that historical differences over fundamental issues may reflect differences of intention and convention rather than anything like a competition over a community of values $[\ldots](1969,52)$

La intención primera del historiador arqueólogo siendo lo que es (sc., el intento por comprender lo que un enunciado dice relativamente a aquello de lo que se habla en el marco dado de un complejo de preguntas y respuestas), es imprescindible para él estar armado contra aquellos movimientos subrepticios de la lectura por los que son introducidos en el texto elementos que son ajenos a dicho texto. De no ser así, en efecto, dichos elementos se introducirían luego en su narración, y harían que el relato perdiera toda referencia a la historia, tornándose en mala literatura. Estas armas son precisamente las que ofrece la historia material: historia de los corpus y de las instituciones.

A partir de lo dicho se responde también a la pregunta inicial: la posibilidad de escapar a la retrospección, o más bien a sus consecuencias "mistificadoras", reside 1) en el tipo de herramientas de que el historiador dispone, y 2) en el objetivo que se da a la historia de la filosofía (puesto que, además de la materia sobre la que el historiador filósofo trabaja, también el objetivo condiciona la elección de las herramientas). Se evita así una objeción posible: que el relativismo histórico no sea una conclusión a la que se llega, sino una presuposición. Lo que se busca en primer lugar no es demostrar la verdad del relativismo histórico, sino simplemente darse los medios para comprender un enunciado producido en un "mundo" diferente, o, si se prefiere, en un horizonte epistémico distinto. Lo que no significa evidentemente "repetir" el enunciado original "tal cual fue expresado", como ya fue 
dicho, sino evidenciar la ley que presidió a su producción y a su ordenamiento en una cierta estructura del saber. ${ }^{39}$

\section{RELEVANCIA Y POSIBILIDAD DE LA DISTINCIÓN ENTRE FILOSOFÍA E HISTORIA DE LA FILOSOFÍA}

La distinción entre filosofía e historia de la filosofía nos parece un hecho filosóficamente relevante, al menos desde el punto de vista de la arqueología, por cuanto esto permite atribuir a la historia de la filosofía, como disciplina filosófica, un objeto específico, la posibilidad de un método particular y una finalidad propia. Cabría preguntar si es efectivamente posible establecer doctrinas o tesis propiamente filosóficas a partir de la historia de la filosofía. En efecto, se considera que una cierta actividad es una disciplina filosófica particular, en la medida en que dicha actividad es capaz de plantear preguntas y proponer tesis respecto de un objeto particular que, de otro modo, sería o más difícil o imposible establecer en las demás disciplinas filosóficas. Habría acaso que señalar, contra las pretensiones filosóficas de la historia de la filosofía, que hay grandes historiadores de la filosofía que consideraron necesario distinguir de manera tajante entre el trabajo de historiador de la filosofía y el de filósofo. Es el caso de Étienne Gilson o de Gilles Deleuze. Esto es significativo por cuanto parece desprenderse de ello que no cabe al historiador de la filosofía proponer una teoría de la predicación, o una doctrina acerca de la relación mente/cuerpo.

Sin embargo, este tipo de argumento no parece decir mucho. El que no sea propio del historiador proponer una teoría de la predicación, o de la relación mente/cuerpo, no quiere decir que no puedan proponer teorías acerca del objeto particular del que tratan. En efecto, no es desde cualquier punto de vista que el filósofo propone una teoría de la predicación o de la relación mente/cuerpo. Lo primero pertenece al filósofo en tanto que hace lógica, mientras que lo segundo en tanto que hace filosofía de la mente. Así, la pregunta parece ser: ¿qué pertenece al filósofo en tanto que hace historia de la filosofía? A esta pregunta, dimos un esbozo de respuesta más arriba: pertenece un conocimiento reflexivo de la filosofía como disciplina, es decir, un conocimiento de la naturaleza del discurso filosófico y de los elementos que lo constituyen. Es necesario dejar en claro desde ya que no se pretende afirmar con esto una prioridad de la historia de la filosofía frente al resto de

39 Tampoco significa esto que se buscará revivir el "mundo" entero en el que dicho enunciado fue producido. Dicho de otro modo, no hay una búsqueda al infinito. 
disciplinas filosóficas: no se trata de prioridades, se trata de especificidad, la que se obtiene por un objeto, un método y una finalidad específicos.

Hemos señalado las tesis en disputa a lo largo del presente trabajo. A la pregunta acerca de la naturaleza de los elementos del discurso filosófico (¿los problemas, objetos, conceptos y principios de la filosofía son universales trans-históricos?), parece haber dos tipos de respuestas opuestas: una "realista" y la otra "nominalista". La arqueología aboga por una posición nominalista. ${ }^{40}$ Más precisamente, el nominalismo de la arqueología es relativista, holista y discontinuista. Con ello, la arqueología se opone así a una historiografía "realista", cuya concepción de los elementos del discurso filosófico sería absolutista, ${ }^{41}$ atomista y continuista. ${ }^{42}$

Con lo anterior se pretende tomar filosóficamente en serio el término "historia" en la expresión "historia de la filosofía". Esto significa que habrá de ser esclarecida la historicidad del discurso filosófico, es decir que, por una parte, habrá que detenerse en el aspecto transformativo o evolutivo, en la variación de las formas discursivas de la filosofía, en el devenir del pensamiento filosófico, y, por otra parte, habrá que considerar el archivo, es decir, el "pasado", no como a un muerto que se lleva a cuestas, ni como a un fantasma que nos atormenta, sino como “energía fósil” (De Libera 2016, 22) en el sentido de una pervivencia del pasado en el presente. Estos dos aspectos

${ }^{40}$ Consultar: Veyne, 2008, 17. En filosofía analítica, por una herencia de la escuela de Oxford de los años 1920, es común oponer el realismo al idealismo, términos con los que son caracterizadas tesis relativas a la gnoseología, no a la ontología. El criterio de distinción radica en entender que lo conocido es o bien una cosa (res) existente extra mentem o bien una idea cuya existencia depende de la mente que la concibe. Desde este punto de vista, nos parece insostenible calificar a la arqueología de "idealista" (además de que, desde Platón al menos, existe un "realismo de las ideas" que sostiene la realidad extra mentem de las ideas). Preferimos por lo mismo retomar la terminología utilizada por P. Veyne en los textos recién referidos para caracterizar la posición filosófica adoptada por Foucault en sus obras de "arqueología", terminología que Foucault parece por cierto haber aceptado; consultar: Foucault 1994, 34. En efecto, la diferencia entre "realismo" y "nominalismo" no radica en la existencia de lo conocido, puesto que ambos consideran que lo conocido existe extra mentem, sino de su naturaleza. Para el realista, esta existencia es la de un universal ejemplificado por casos cada vez particulares, para el nominalista, se trata de una serie de singulares que, por una abstracción indebida que suprime ilegítimamente las diferencias individuales, son asimilados en una idea general.

41 Preferimos utilizar aquí el término "absolutista", no "objetivista", para oponerlo a "relativista", primero, porque con ello se evita una concepción psicologizante del "relativismo", asimilado a un vulgar "subjetivismo", y segundo, porque la idea de una independencia radical de los problemas, tesis y conceptos a las circunstancias de su formulación en la historia parece ser mejor caracterizada por el término "absoluto" que por "objetivo". Por último, el concepto de absoluto ha sido tradicionalmente opuesto al de relativo.

42 Estamos proponiendo casos opuestos de figuras extremas. Por supuesto, hay una gama de combinaciones posibles entre estos dos tipos de historiografía filosófica. Una de ellas es de hecho la de C. Panaccio. Para la distinción entre estas dos posiciones y sus combinaciones posibles, consultar: Engel 1997, 179-208, en particular 188 y ss. 
pueden parecer a primera vista contradictorios, en la medida en que el primero hace énfasis en las rupturas epistémicas, esto es, en las discontinuidades, mientras que el segundo, por el contrario, parece implicar una cierta forma de continuismo. Es necesario por lo mismo detenerse en estos dos aspectos, a fin de esclarecer esta aparente contradicción.

Por una parte, al hacer énfasis en las "mutaciones del discurso", en las transformaciones epistémicas, la arqueología filosófica pretende oponerse a aquellas historiografías que suponen una línea única de transformación, por cuanto esta suposición implica toda una mitología del progreso. Por el contrario, la arqueología afirma la pluralidad de los modos del pensar o, más bien, de las formas que un discurso puede tomar según la episteme que lo rige. Por otra parte, la asimilación (metafórica) del archivo a una "energía fósil" es la interpretación en términos arqueológicos de la tesis collingwoodiana de la continuación del pasado en el presente. Según Collingwood, en efecto, "el pasado estudiado por el historiador no es un pasado muerto, sino que, en cierto sentido, sigue vivo en el presente". 43 Si aplicamos esto al discurso filosófico, esto significa según Alain de Libera que el pasado, bajo la forma de "dispositivos conceptuales" o de "esquemas argumentativos", sigue nutriendo a la filosofía contemporánea de manera insospechada y la mayor parte de las veces à l'insu de los filósofos. ${ }^{44}$ La "energía fósil" del archivo es lo que permite las "migraciones conceptuales", es decir, la aparición, en un contecto (CPR) completamente distinto al contexto de origen, de dichos dispositivos y esquemas, presentados como elementos anónimos y racionales.

En realidad, estos dos aspectos (continuidad y discontinuidad) no son contradictorios, sino, por el contrario, complementarios. Que en la trama o "red" que constituye un CPR del presente, relativo a una episteme que rige tal discurso filosófico en la actualidad, pueda hallarse (y se halle necesariamente) un "hilo" (i.e. un dispositivo conceptual) que remite a otros CPR, relativos a otras epistemes, es la condición sin la cual la idea misma de transformación sería inconcebible. Es, por lo tanto, la condición de toda historia, como serie de transformaciones que pueden ser trazadas. Un cambio de

43 El original en inglés dice: "the past which an historian studies is not a dead past, but a past which in some sense is still living in the present" $(1939,97)$. Este "primer principio" de su filosofía de la historia se opone en apariencia al discontinuismo, por cuanto establece que, en la medida en que la historia se constituye de "procesos", entonces, "if a process P1 turns into a process P2, there is no dividing line at which P1 stops and P2 begins" (1939, 98). Sin embargo, como se verá en lo que sigue, continuidad y discontinuidad son conceptos relativos y complementarios.

44 Alain de Libera $(2008,83-93 ; 133-135)$ muestra de manera rigurosa la continuidad existente entre la teoría strawsoniana de la persona, la doctrina cartesiana de la unión del cuerpo y del alma y la doctrina teológica de la Encarnación y de la Resurrección. 
episteme, una "mutación del discurso", no implica que, de un día para otro, empecemos a hablar en otra lengua y a ver otro mundo; "lo que cambia es la configuración sorda sobre la que el lenguaje se apoya", y es eso lo que permite ver otra cosa y que esa cosa se vuelva enunciable; es de ese modo también que se redefine la "distribución originaria de lo visible y de lo invisible", y con ella "de lo que se habla y de lo que se calla" (Foucault, 1963, vii). ${ }^{45} \mathrm{La}$ arqueología filosófica muestra que, la mayor parte de las veces, ahí donde se cree ver una continuidad (el "sujeto moderno" de Descartes a Husserl), hay en realidad una ruptura infranqueable (Kant), y que, ahí donde se creía ver cosas absolutamente distintas (la unión de las dos naturalezas en Cristo y la teoría de la persona en Strawson), hay en realidad un elemento conceptual de continuidad que había pasado hasta entonces inadvertido.

Por último, es también esta continuación o pervivencia del pasado en el presente lo que posibilita el "Re-enactment", es decir, la re-efectuación, reactivación o re-ejecución del pensamiento pasado por el historiador de la filosofía (Collingwood 1939, 111-115). La necesidad de comprender un enunciado, es decir, de pensarlo según el propósito que le diera el autor del pasado, lleva al historiador a resituar ese enunciado como respuesta a una pregunta. La posibilidad misma de un conocimiento verdadero, en términos de referencia, de una tesis filosófica del pasado depende de que una comprensión sea pensada, no sólo "en los términos del filósofo" del pasado, sino también dentro del CPR al que pertenece. ${ }^{46}$ El teorema del "Re-enactment" afirma que "el conocimiento histórico es la re-efectuación [re-enactment] en la mente del historiador del pensamiento del que estaba haciendo la historia" (Collingwood 1969, 112). ${ }^{47}$ Ahora bien, esto pareciera implicar que existe una suerte de identificación entre la mente del historiador y la del filósofo del pasado. De hecho, esto es lo que se desprende de una especie de "máxima" enunciada por Alain de Libera según la cual: "la única forma de hacer historia de la filosofía medieval es haciendo filosofía medieval" (De Libera, 2016, 18). Sin embargo, al mismo tiempo, Collingwood señala una diferencia insalvable entre el pensamiento-enunciado de origen y el pensa-

45 El término "originario" hace referencia aquí no a un origen absoluto, sino relativo a tal o cual formación discursiva, tal o cual episteme.

46 Para una discusión de este punto, consultar: Bernard Williams 2006, 345-351.

47 Este teorema se basa en otro según el cual "toda historia es historia del pensamiento"; ver: Collingwood 1969, 110. Esto significa que sólo el pensamiento puede ser objeto de historia, puesto que sólo el pensamiento, es decir, la reflexión a partir de la cual una acción es llevada a cabo (su "intencionalidad") y de la que tenemos noticia por sus productos (obra, texto, etc.), da la razón de una acción humana. Dicho en otros términos: si una acción es un medio por el que se intentó obtener un cierto resultado, entonces, ella puede ser considerada como la "respuesta" a una cierta "pregunta", que es precisamente lo que el historiador debe intentar encontrar. 
miento-enunciado mentado por el historiador, a saber, "el contexto" (Collingwood 1969, 113). En efecto, el pensamiento-enunciado pasado no es reefectuado en el mismo "contexto" que aquel en el que fue proferido: tanto el contexto práctico como el contexto teórico cambian radicalmente. Collingwood considera, en efecto, que el pensamiento-enunciado pasado se presenta "encapsulado, no libre" $(1969,113)$. Esto significa que, en su re-efectuación, el pensamiento-enunciado pasado no tendrá los mismos efectos, por cuanto no hará parte de la misma cadena de causas ni de razones, sino de otra, a saber, precisamente, la del relato del historiador.

Vemos entonces que hay dos usos diferentes de los enunciados pasados en el presente, según este uso sea consciente o inconsciente. Estos dos usos llevan el cuestionamiento arqueológico hacia dos direcciones distintas: por una parte, hacia el análisis crítico de las diversas formas narrativas que los filósofos han introducido subrepticiamente en su quehacer filosófico, quehacer que reivindican, sin embargo, como completamente "puro" de toda narración. Por otra parte, se puede esclarecer así la cuestión de la relación entre el uso de los enunciados del pasado y la finalidad de la historia de la filosofía tal como es practicada por la arqueología. Veamos, para terminar, estas dos cuestiones de manera más detallada.

1) Respecto del primer punto, uno de los momentos fundamentales del método arqueológico pasa por la elaboración de una reflexión en torno a los modos en que la filosofía (se) ha contado su propia historia. Es acaso lo que podría llamarse la parte "deconstructiva" de la arqueología de los discursos filosóficos, pues consiste en una deconstrucción de los relatos filosóficos. No es este el lugar para mostrar este aspecto de la arqueología mediante un ejemplo, lo que tomaría demasiado tiempo y que puede, además, ser fácilmente consultado en las obras de Alain de Libera (2016, 85-176); por ello, propondré aquí una mera descripción. Básicamente, se trata de mostrar que la historiografía filosófica "tradicional” ha dejado incuestionado un aspecto fundamental para la comprensión que tenemos de lo que es un problema, una tesis o un concepto filosófico, a saber, el modo en que la historiografía filosófica, precisamente, ha tradicionalmente "tratado" o, más bien, "reconstruido" (o acaso simplemente construido) los problemas, tesis y conceptos de la filosofía del pasado. Este momento deconstructivo de la arqueología no solo es importante porque con ello se hace posible un conocimiento crítico de la historia de los elementos del discurso filosófico. Su importancia radica sobre todo en el hecho de que muestra que los "esquemas narrativos", sobre los que es construido el relato historiográfico de un problema filosófico, se 
sostienen en "esquemas conceptuales". ${ }^{48}$ Alain de Libera mostró cómo este cruce de esquemas narrativos y conceptuales producía, en dos figuras centrales para la invención de la querella de los universales de comienzos del siglo XIX, Dugald Stewart (1753-1828) y Joseph-Marie de Gérando (17721842), una serie de categorías (nominalismo, conceptualismo, realismo) por la que es interpretada la "materia medieval" dando origen a toda una serie de "mitologías" (en el sentido de Skinner 1969): mitología de las doctrinas, de la prolepsis, etc (De Libera 2016, 182-183). Ahora bien, acaso lo más interesante aquí sea el hecho de que, de este modo, la historia -no crítica- de la filosofía definía el modo en que los problemas filosóficos deben ser planteados y las posiciones posibles que podían ser adoptadas en filosofía.

De lo anterior, se puede, quizá, desprender la siguiente tesis: en el argumento filosófico más puramente formal subsistirá siempre, necesariamente, un "resto" de literatura (por así decir), esto es, de esquemas narrativos impregnados a ese argumento bajo la forma de figuras, de tópoi retóri$\cos ^{49}$ (gracias a los cuales, de hecho, la filosofía será siempre otra cosa que las matemáticas). Esto no es menor, por cuanto es en esta reflexión que se esclarece uno de los puntos centrales que la arqueología busca señalar: la interpenetración de la historia y de la filosofía - o, más bien, el hecho de que, en tanto que objeto del mundo, la filosofía obedece a las leyes de ese mundo, una de las cuales es, sin duda, que dichos objetos son por naturaleza históricos, se han constituido históricamente, es decir, deben a su historia, a su génesis histórica, su forma y su estructura actual. ${ }^{50}$ Esto significa que la serie de determinaciones internas que han hecho que la forma actual del discurso filosófico se vuelva necesaria solo podrá hallarse en su historia concebida como historia de los corpus e historia de las redes conceptuales.

2) Por último, es necesario recordar aquí que la arqueología tiene una ambición propiamente filosófica: su campo de reflexión último es la historia del pensamiento y su fin último es la determinación de lo que ha hecho que una forma del pensamiento se vuelva necesaria. En el caso particular de la arqueología conceptual, su campo estará constituido por aquel modo del pensar que se ha hecho llamar filosófico y su fin será la determinación de

${ }^{48}$ Alain de Libera, L'archéologie philosophique, 102. Respecto al caso de la historiografía en torno a la "querella de los universales", que cristalizará en la obra de Victor Cousin, y al rol de Dugald Stewart y de Joseph-Marie De Gérando, no podemos sino remitir a Alain de Libera 2016, 27-48 y 85-176.

${ }^{49}$ Consultar, por ejemplo, De Libera 2016, 158.

50 En esto el proyecto arqueológico coincide con la finalidad de la historiografía tal como es concebida por Kurt Flasch $(2010,265-305)$. En efecto, la historia de la filosofía, dice el filósofo alemán, consiste en "hacer perceptible el inexorable transcurrir del tiempo en el seno mismo del pensamiento puro", (Flasch 2010, 267). Para mayor precisión acerca de la "relación al tiempo" del pensamiento, ver: Flasch 2010, 296-298. 
aquello que ha vuelto necesarias las formas del pensar filosófico actual. ${ }^{51}$ Es desde este punto de vista que debe apreciarse el uso que el historiador hace en su reconstrucción histórica de las transformaciones del discurso filosófico de los enunciados: la reconstrucción de los argumentos, tesis, conceptos pasados, son dispuestos en el orden del discurso que es el orden de una cierta manera de narrar, de un cierto relato. Si el relato tiene límites, si no desborda en una indefinida descripción arbitraria de objetos más o menos exóticos, es porque sigue una "intriga" (De Libera 2008, 12)..$^{52}$ Como la "visión retrospectiva", propia de las construcciones teleológicas (como es el caso de los relatos de la historiografía progresista), la intriga, que el historiador se da por tarea narrar, implica también un corte singular operado sobre un "campo objetivo de acontecimientos", el cual, en el caso de la historia de la filosofía, es un campo de "acontecimientos conceptuales" (De Libera $2008,12)$. Sin embargo, a diferencia de las pretensiones totalizantes de la historiografía progresista, el filósofo arqueólogo sabe que no puede "describir la totalidad de este campo, puesto que todo itinerario hace elecciones y no puede pasar por todas partes" (Veyne 1979; citado por De Libera 2008, 12); y, más generalmente, a diferencia de las historias narradas a partir de una visión retrospectiva, que impone a dicho campo cortes a partir de categorías cuya validez supone de suyo evidente, el relato arqueológico propone, a partir de un diagnóstico crítico de los discursos presentes en torno a un objeto supuestamente trans-histórico (para Foucault, se trata de los "universales antropológicos"; para De Libera, problemas, tesis, conceptos y argumentos), un relato explicativo que dé cuenta de la historicidad de dichos objetos.

En este sentido, la arqueología radicaliza la historicidad de la filosofía y de sus elementos. La arqueología filosófica pretende demostrar la historicidad de todo "objeto filosófico" dado, lo que significa dar cuenta a la vez de la necesidad de su existencia (por la determinación de los a priori históricos) y de la contingencia de su modo de ser (por la crítica de la visión retrospectiva). ${ }^{53}$ Así las cosas, el uso de los enunciados del pasado en el relato arqueológico depende de una intriga que debe combinar en su relato estas dos modalidades. Se procede así a una reflexión sobre aquellos presupuestos (los "dispositivos textuales y conceptuales") que determinan las diversas formas

${ }^{51}$ Consultar: Foucault 2007.

52 Con respecto a los conceptos de "intriga", íntimamente ligado al de "campo de acontecimientos", consultar Veyne 2008, 35-69.

53 Desde cierto punto de vista, se puede decir que el tipo de historiografía que practica el arqueólogo obedece al objetivo historicista formulado por K. Flasch: se trata de "hacer ver' la fuerza de las necesidades cotidianas, del azar y del tiempo, en el corazón mismo de las especulaciones más elevadas" $(2010,275)$. 
que toma dicho pensamiento. En palabras de Alain de Libera, la arqueología filosófica demuestra que:

al tirar de un hilo (...) se saca a luz toda la red en la que pensamos y que, de cierto modo, nos constriñe <a pensar de la manera en que lo hacemos>. Las preguntas que nos hacemos no caen del cielo; son tejidas, trenzadas en redes de nociones, de ejemplos, de preguntas, de problemas, de tesis, de distinciones que desde siempre ya nos preceden. Entramos en este campo creyendo que somos soberanamente libres de hacer las preguntas que hacemos y responder de la manera que respondemos. Pero, en realidad, no hacemos más que tomar un itinerario que está ya muy ampliamente construido y que nos prescribe un cierto número de recorridos. $(2016,203)$

\section{CONCLUSIÓN}

A mi modo de ver, aunque sin desmedro de la legitimidad de las distinciones institucionales tales como "filosofía" e "historia de la filosofía", el historiador de la filosofía es un filósofo a tiempo completo; y lo es, quizá, bajo cualquiera de sus formas. Se puede tener razones filosóficas fuertes para ser "platónico" o "aristotélico" o "tomista" o "averroista" en pleno siglo XXI. Por supuesto, el historiador de la filosofía que tiene razones filosóficas para escribir un nuevo comentario sobre Platón no entrará en cualquier debate filosófico contemporáneo, sino en aquel a que apunta la pregunta que dirige su investigación. No es la "urgencia del presente" lo que dirige nuestras preguntas, sino presupuestos que es menester esforzarse por esclarecer. De hecho, esta "exigencia del presente" (la exigencia de "ser actuales") merecería ser elucidada como cualquier otro presupuesto.

Sea como fuere, esperamos haber dado una visión general del problema que plantea la relación entre historia de la filosofía y la filosofía al interior mismo de la historia de la filosofía, a partir de la tensión entre estas dos categorías en apariencia opuestas: "historia" por una parte, "filosofía" por la otra. Hemos querido mostrar que, desde el punto de vista de la arqueología, la relación entre historia de la filosofía y filosofía no se reduce a una disyuntiva (o bien "historia y filosofía" o bien "historia o filosofía"). La razón está en que se trata de considerar a la filosofía en su historicidad, como discurso históricamente constituido, es decir, se trata de considerar la historicidad intrínseca al discurso y a los discursos filosóficos. La disyunción presupone que se trata de dos elementos extrínsecos y heterogéneos el uno al otro. Eso es precisamente lo que la arqueología filosófica entiende refutar; pero para ello no basta con leer o escribir acerca del método arqueológico. Es necesario practicarlo. 


\section{BIBLIOGRAFIA}

Aristóteles, Metafísica. 1998. Edición trilingüe por Valentín García Yebra. Segunda edición revisada. Madrid: Gredos.

Apel, Karl-Otto, Barnes, Jonathan y Bellone, Enrico. 2000. Un siècle de philosophie, 1999-2000. Paris: Gallimard-Centre Pompidou.

Barnes, Jonathan. 2000. "La philosophie et ses histoires." En Un siècle de philosophie, 1999-2000, Appel, Karl-Otto, Barnes, Jonathan y Bellone, Enrico, 552-587. Paris: Gallimard-Centre Pompidou.

—. "Le soleil de Platon vu avec des lunettes analytiques." Rue Descartes $\mathrm{N}^{\circ}$ 1-2 (1992): 81-92.

Boss, Gilbert. La philosophie et son histoire. Zurich: Éditions du Grand Midi, 1994.

Brenet, Jean-Baptiste. “Averroes a-t-il inventé une théorie des deux sujets de la pensée?” Tópicos $\mathrm{N}^{\circ} 29$ (2005): 53-86.

Castello Dubra, Julio. "La actualidad de la filosofía medieval: un reciente debate historiográfico." En Presente y pasado de la filosofía, de Alejandro Cassini y Laura Skerk, 195-244. Buenos Aires: Editorial de la Facultad de Filosofía y Letras de la Universidad de Buenos Aires, 2010.

Collingwood, Robin George. Idea de la historia. Edición revisada que incluye las conferencias de 1926-1928. México: Fondo de Cultura Económica, 2010.

-. An Essay on Metaphysics. Oxford: Clarendon Press, 1940.

-. An Autobiography. Londres-Oxford-New York: Oxford University Press, 1939.

Cortés Cuadra, Juan Vicente. "El estilo arquelógico de Alain de Libera. Nota sobre la relación entre historia de la filosofía y filosofía." Ideas y valores. Revista colombiana de filosofía vol. 67, № 167 (2018): 363-374.

De Libera, Alain. L'archéologie philosophique. Paris: Vrin, 2016.

-. Archéologie du sujet. Vol. III. La double révolution. Tome 1, L'acte de penser. Paris: Vrin, 2014a.

-. La querelle des universaux. De Platon à la fin du Moyen Âge. Edition augmentée d'une Postface. Paris: Seuil, 2014b.

—. Archéologie du sujet. Vol. II. La quête de l'identité. Paris: Vrin, 2008.

—. Archéologie du sujet. Vol. I. La naissance du sujet. Paris: Vrin, 2007.

—. La philosphie médiévale. Paris: Presses Universitaires de France, 2004.

—. "Archéologie et reconstruction. Sur la méthode en histoire de la philosophie médiévale." En Un siècle de philosophie, 1999-2000, de Karl-Otto Apel, Jonathan Barnes y Enrico Bellone, 552-587. Paris: GallimardCentre Pompidou, 2000.

—. "Le relativisme historique. Théorie des 'complexes questions-réponses' et 'traçabilité'." Les Études philosophiques $\mathrm{N}^{\circ} 4$ (1999): 479-494.

—. "Retour à la philosophie médiévale?" Le Débat Nº 72 (1992): 145-158. 
Engel, Pascal. “Retour aval.” Les Études philosophique N 4 (1999): 453-463.

—. La Dispute. Une introduction à la philosophie analytique. Paris: Minuit, 1997.

Emar, Juan. Cavilaciones. Santiago: La Pollera, 2014.

Flasch, Kurt. Introduction à la philosophie médiévale, traducido del alemán por J. de Bourgknecht, R. Imbach y F.-X. Putallaz. Fribourg-Paris: Academic Press-Editions du Cerf, 2010.

Foucault, Michel. "Les monstruosités de la critique.", traducido del inglés por F. Durand-Bogaert. En Dits et écrits, II, 1970-1975, de Michel Foucault, 219-223. Paris: Gallimard, 1994.

—. L'archéologie du savoir. Paris: Gallimard, 1969.

- Les mots et les choses. Une archéologie des sciences humaines. Paris: Gallimard, 1966.

—. Naissance de la clinique. PUF: Paris, 1963.

Glock, Hans-Johann. "Analytic Philosophy and History: A Mismatch?" Mind vol.117 N 468 (2008): 867-897.

Gómez Romero, Isidro. "Concepto y método de la Historia de la Filosofía en la obra de Wilhem Windelband." Anales del Seminario de Historia de la Filosofía vol.1 (1980): 219-239.

Gouhier, Henri. La pensée religieuse de Descartes. Paris: Vrin, 1925.

Halphen, Louis. "Les universités au XIIIe siècle. I. La conquête de l'autonomie." Revue historique. T. 166, f. 2 (1931): 217-238.

Kant, Immanuel. Los progresos de la metafísica. México: Fondo de Cultura Económica, 2008.

Krüger, Lorenz. “¿Por qué estudiamos la historia de la filosofía?” En La filosofía en la historia. Ensayos de historiografía de la filosofía, de Richard Rorty, Jerome B. Schneewind, Quentin Skinner, 99-126. Buenos AiresBarcelona: Paidós, 1990.

Lovejoy, Arthur. La gran cadena del ser. Historia de una idea. Barcelona: Icaria, 1983.

MacIntyre, Alasdair. "La relación de la filosofía con su pasado." En La filosofía en la historia. Ensayos de historiografía de la filosofía, de Richard Rorty, Jerome B. Schneewind, Quentin Skinner, 49-67. Buenos Aires-Barcelona: Paidós, 1990.

Mulligan, Kevin. "Sur l'histoire de l'approche analytique de l'histoire de la philosophie: de Bolzano et Brentano à Bennett et Barnes." En Philosophie analytique et histoire de la philosophie, de Jean-Michel Vienne, 61103. Paris: Vrin, 1997.

Oyarzun, Pablo. El dedo de Diógenes. La anécdota en filosofía. Santiago: Dolmen, 1996.

Panaccio, Claude. "De la reconstruction en histoire de la philosophie." En $L a$ philosophie et son histoire, de Gilbert Boss, 173-195. Zurich: Éditions du Grand Midi, 1994. 
Peden, Knox. Spinoza contra Phenomenology. French Rationalism from Cavaillès to Deleuze. Stanford: Stanford University Press, 2014.

Placencia, Luis. "Consideraciones sobre la distinción entre "filosofía analítica" y "filosofía continental"." Mutatis Mutandi № 9 (2017): 7-16.

Rorty, Richard, Schneewind, J.B. y Skinner, Quentin. La filosofía en la historia. Ensayos de historiografía de la filosofía. Buenos Aires-Barcelona: Paidós, 1990.

-. Philosophy in the History. Essays on the historiography of philosophy. Cambridge: Cambridge University Press, 1984.

Serres, Michel. Hermès. III. La traduction. Paris: Minuit, 1974.

Skinner, Quentin. "Meaning and Understanding in the History of Ideas." History and Theory, vol. VIII N²1 (1969): 3-53.

Sorrel, Tom, y Rogers, G.A.J.. Analitic Philosophy and History of Philosophy. Oxford: Clarendon Press, 2005

Steiner, George "The Mandarin of the Hour. Michel Foucault." The New York Times, 28 de febrero, 1971.

Tennemann, Wilhelm. Manuel de l'histoire de la philosophie. Tomo I, traducido del alemán por V. Cousin Paris: A. Sautelet et Cie. Éditeurs, 1829

Veyne, Paul. Foucault. Sa pensée, sa personne. Paris: Albin Michel, 2008.

-. Comment on écrit l'histoire. Suivi de Foucault révolutionne l'histoire. Paris: Seuil, 1979.

Vienne, Jean-Michel. Philosophie analytique et histoire de la philosophie. Paris: Vrin, 1997.

Williams, Bernard. The Sense of the Past. Essays in the History of Philosophy. Princeton-Oxford: Princeton University Press, 2006. 